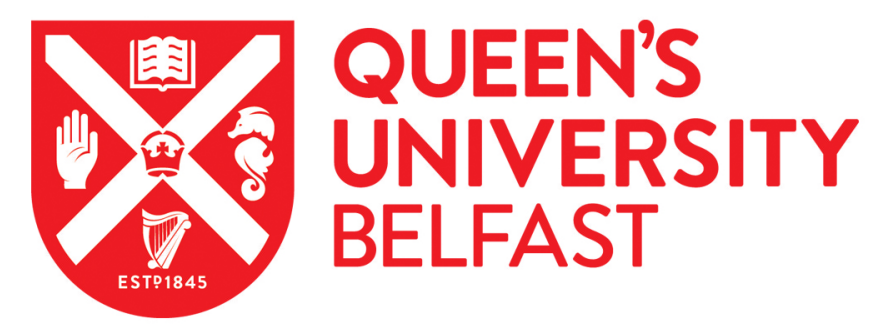

\title{
Investigation on Thermomechanical Properties of Poly (I-lactic acid) for the Stretch Blow Moulding Process of Bioresorbable Vascular Scaffold
}

Wei, H., \& Menary, G. (2017). Investigation on Thermomechanical Properties of Poly (I-lactic acid) for the Stretch Blow Moulding Process of Bioresorbable Vascular Scaffold. In 20th International ESAFORM Conference on Material Forming: Proceedings (Vol. 1896). [060002] American Institute of Physics.

https://doi.org/10.1063/1.5008065

Published in:

20th International ESAFORM Conference on Material Forming: Proceedings

Document Version:

Peer reviewed version

Queen's University Belfast - Research Portal:

Link to publication record in Queen's University Belfast Research Portal

Publisher rights

(c) 2017 The Authors.

This work is made available online in accordance with the publisher's policies. Please refer to any applicable terms of use of the publisher

General rights

Copyright for the publications made accessible via the Queen's University Belfast Research Portal is retained by the author(s) and / or other copyright owners and it is a condition of accessing these publications that users recognise and abide by the legal requirements associated with these rights.

\section{Take down policy}

The Research Portal is Queen's institutional repository that provides access to Queen's research output. Every effort has been made to ensure that content in the Research Portal does not infringe any person's rights, or applicable UK laws. If you discover content in the

Research Portal that you believe breaches copyright or violates any law, please contact openaccess@qub.ac.uk. 


\title{
Investigation on Thermomechanical Properties of Poly (l- lactic acid) for the Stretch Blow Moulding Process of Bioresorbable Vascular Scaffold
}

\author{
Huidong Wei ${ }^{1, \text { a) }}$ and Gary Menary ${ }^{1, \text { b) }}$ \\ ${ }^{1}$ School of Mechanical and Aerospace Engineering, Queen's University Belfast \\ (123 Stranmillis Road, Ashby Building, BT9 5AH, Belfast, UK) \\ a)hwei02@qub.ac.uk \\ b)g.menary@qub.ac.uk
}

\begin{abstract}
Stretch blow moulding process has been used for the manufacture of bioresorbable vascular scaffold (BVS) made by poly (l-lactic acid) (PLLA) to improve its mechanical performance. In order to better understand the process, thermomechanical properties of PLLA were investigated by experimental method. Extruded PLLA sheets were biaxial stretched under strain rate of $1 \mathrm{~s}^{-1}, 4 \mathrm{~s}^{-1}$ and $16 \mathrm{~s}^{-1}$ to simulate the deformation process applicable in the blow moulding process. Both the equal-biaxial stretch and constant-width stretch were conducted by an in-house developed equipment. By differential scanning calorimeter (DSC), thermal analysis for materials before and after stretch were compared to evaluate the microstructural change of PLLA materials in the deformation process. A constitutive model based on glass rubber model was presented to simulate the mechanical behaviour of PLLA above glass transition under biaxial deformation.
\end{abstract}

\section{INTRODUCTION}

Poly (L-lactic acid) is used to manufacture bioresorbable vascular scaffold (BVS) for its biodegradable properties. However, the relatively low mechanical properties of PLLA BVS induced a thicker strut thickness, ranging from 100 to 200microns by comparing the metallic scaffolds with strut thickness of less than 100microns. As a result, the PLLA BVS is now just recommended to be applied for situations, where the diameter of human artery is bigger than $2.5 \mathrm{~mm}$. For polymers, by introducing biaxial stretch at temperature above glass transition, the molecular chains can be greatly oriented and after stretch the mechanical characteristics below glass transition can be improved. For poly (lactic-acid) (PLA), both the tensile strength and elongation at break increased by up to $10 \%$ at different stretch ratios and temperature conditions by biaxial stretch [1]. This method has now began to be applied for the manufacture of PLLA BVS by introducing a stretch blow moulding process [2]. The extruded PLLA tube is placed in a mold and the temperature is increased to above its glass transition. Then the tube is pressurized to be inflated and the end of tube is also stretched simultaneously to introduce molecular orientation in both circumferential and longitudinal directions. The mechanical properties of tubes after stretch are strongly depended on the processing conditions, such as the stretch ratio in two directions, forming temperatures and pressure [3].

The stress-strain relations in the deformation of PLA above glass transition showed strong dependence on the temperature conditions [1]. The strain hardening at large strains is more obvious at low temperature conditions. As the temperature increases, bigger stretch ratio is required for the onset of strain hardening. The equal biaxial stretch can induce a higher stress at the same strain than the constant-width stretch. All this phenomenon is very similar to the deformation of other thermoplastics, like PET. High strain rate usually exists in the stretch blow moulding process [4]. However, the previous research on the deformation of PLA material usually concentrated on the material characterization at low strain rates. In fact, the mechanism is quite different in the deformation at different strain rates. At low strain rate, the crystallization of PLA materials happens during the deformation process [5]. But when the 
strain rate is higher enough than the chain retraction, the onset of crystallization will be delayed until near the termination of deformation process [6].

The shape evolution can be better explained and predicted in the stretch blow moulding process by the numerical simulation with an effective constitutive model, which has been widely used in the packaging industry for PET material. It will be more helpful for the manufacture of PLLA BVS because the dimension of the product is much smaller and it is more difficult to investigate the deformation behaivour. As there is similar mechanical behaviour between PET and PLLA, the glass-rubber model developed by Buckley etc. [7, 8, 9] has been successfully used to describe the thermomechanical properties of PET is a good choice to simulate nonlinear viscoelastic behaviour of PLLA above glass transition. The GR model is a three dimensional constitutive model based on the additivity of free energy from bond distortion and conformation perturbation. It was modified by implementing the effect of entanglement slippage to describe the varied strain hardening behaviour of polymers at different temperatures.

In the work of this paper, the thermomechanical properties of PLLA at temperatures above glass transition are investigated by biaxial stretching method. The strain rates adopted are ranging from $1 \mathrm{~s}^{-1}$ to $16 \mathrm{~s}^{-1}$, i.e. at conditions that can be applicable to the blow moulding process for the manufacture of BVS. PLLA material before and after stretch is characterized by the thermal analysis to detect the change of microstructure after the biaxial deformation. A constitutive model originated from GR model is presented based on experimental data to simulate the mechanical PLLA at biaxial deformation.

\section{EXPERIMENTAL}

\section{Material Preparation}

The raw PLLA pellets were dried and prepared for extrusion work. PLLA sheets with thickness of $0.5 \mathrm{~mm}$ were extruded by a single-screw extruder. For the biaxial stretch test, the sheet samples were cut into $75 \mathrm{mmX} 75 \mathrm{~mm}$ square specimen to be ready for mechanical test. An ink mark is made on the sheet to guarantee a homogeneous deformation during the stretching process. And the sheet before stretch and films after stretch were cut into small pieces with the mass of $6 \mathrm{mg}$ to $10 \mathrm{mg}$ and put into the aluminum cans for thermal test.

\section{Biaxial Stretch}

Biaxial stretch was conducted by an in-house developed machine in Queen's University Belfast. A square sheet sample can be fixed by four groups of grips in two directions in the machine, which is shown in Fig.1 (a). Both the equal biaxial stretch (EB) and constant-width stretch (CW) in Fig.1 (b) can be made by controlling the stretch in two directions. Two heaters at the top and bottom of the sheets supplied hot air to increase the temperature of sheet to desired values by real-time control and measurement with two thermocouples near the sheet. Four temperature conditions $80^{\circ} \mathrm{C}, 85^{\circ} \mathrm{C}, 90^{\circ} \mathrm{C}, 95^{\circ} \mathrm{C}$ were set during each test. Stretching speed corresponding to the nominal strain rate of $1 \mathrm{~s}^{-1}, 4 \mathrm{~s}^{-1}$ and $16 \mathrm{~s}^{-1}$ was reached by controlling the speed of servo motor. Forces in two directions during the stretching process were measured by two load cells fixed on one grip of the two axes. LabView on a computer is used to control and record the real-time displacement and force data in the deformation process.

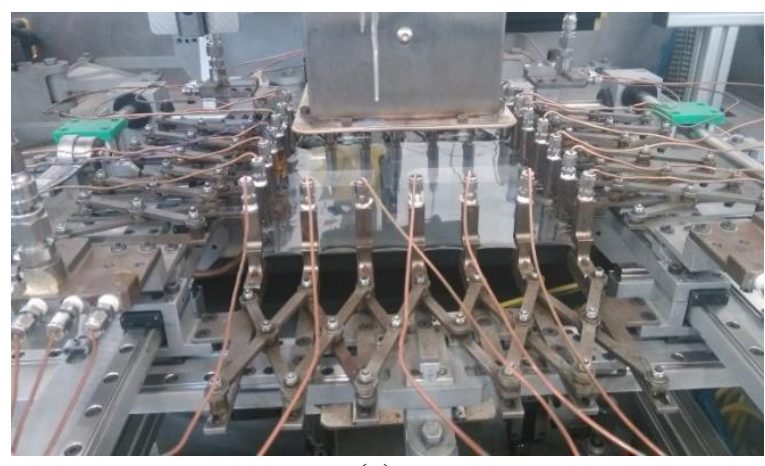

(a)

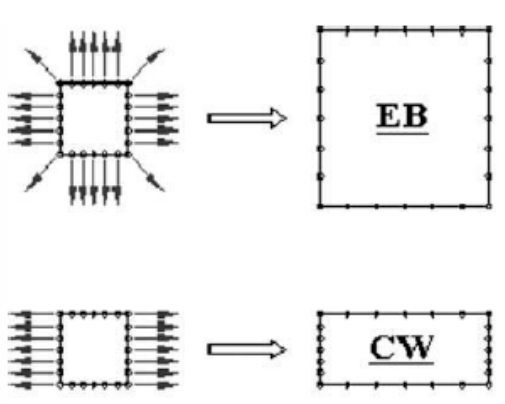

(b)

FIGURE 1. Biaxial stretching machine (a) and the deformation mode in the test (b) 


\section{Thermal Test}

Thermal test for PLLA materials before and after stretch was conducted by differential scanning calorimetry (DSC) method. The model DSC 6 from PerkinElmer, UK was used in the test. It consists of a computer-controlled furnace and heat or cool the polymer samples and a reference sample independently from temperature $30^{\circ} \mathrm{C}$ to $300^{\circ} \mathrm{C}$ at a rate of $20^{\circ} \mathrm{C} / \mathrm{min}$. The temperatures of glass transition, cold crystallization and melting can be obtained from analyzing the properties of the heat flow curves.

\section{Constitutive Model}

The total stress tensor in the glass rubber model (GR) $\sigma$ consists of a bond-stretching stress $\sigma^{b}$ and a conformational stress $\sigma^{c}$ by equation (1).

$$
\sigma=\sigma^{b}+\sigma^{c}
$$

The bond-stretching part has Hooke elasticity and non-Newtonian viscosity that can be express as equation (2).

$$
2 G^{b} \frac{d e_{i}}{d t}=\frac{d s_{i}^{b}}{d t}+\frac{s_{i}^{b}}{\tau}(i=1,2,3)
$$

Where $G^{b}$ is shear modulus and $\tau$ is relaxation time, which is defined as $\tau=\frac{\mu}{2 G^{b}}$ and $\mu$ is shear viscosity.

The nonlinear effect for the viscous part is incorporated into relaxation time $\tau$ by equation (3), where the effects of evolution from stress $\left(a_{\sigma, j}\right)$, structure $\left(a_{s, j}\right)$ and temperature $\left(a_{T}\right)$ are considered.

$$
\tau=a_{\sigma, j} a_{s, j} a_{T} \tau_{0}^{*}(j=1,2,3)
$$

The conformational part has hyper-elasticity and non-Newtonian viscosity that can be express as equation (4).

$$
\frac{d e_{i}}{d t}=\frac{1}{\lambda_{i}^{n}} \sum_{j=1}^{3} C_{i j}^{c} \frac{d \sigma_{j}^{c}}{d t}+\frac{s_{i}^{c}}{\gamma}(i=1,2,3)
$$

Where $\lambda_{i}^{n}$ is invariant of the network stretch, $\gamma$ is conformational viscosity and $C_{i j}^{c}$ is the tangent conformational compliance matrix that can be obtained from the Edwards-Vilgis model by equation (5), which consider the contribution from slip-links and cross-links.

$$
A^{\mathrm{c}}=\frac{N_{e} k_{b} T}{2}\left(\frac{(1+\eta)\left(1-\alpha^{2}\right)}{1-\alpha^{2} \sum_{i=1}^{3} \lambda_{i}^{2}} \sum_{i=1}^{3} \frac{\lambda_{i}^{2}}{1+\eta \lambda_{i}^{2}}+\sum_{i=1}^{3} \ln \left(1+\eta \lambda_{i}^{2}\right)+\ln \left(1-\alpha^{2} \sum_{i=1}^{3} \lambda_{i}^{2}\right)\right)
$$

Where $A^{\mathrm{c}}$ is strain energy function, $N_{e}$ is number density of slip-links, $k_{b}$ is Boltzmann constant, $\eta$ is freedom of movement of slip-links, $\alpha$ is the degree of inextensibility of chains. More details on the constitutive model can be obtained on the reference $[7,8,9]$.

A homogeneous deformation is considered during the biaxial stretch test under EB and CW deformation. By incompressible assumption, the deformation properties can be simulated by an explicit integration method with the glass-rubber model [10].

\section{RESULT}

\section{Mechanical Behavior}

The thermomechanical properties of PLLA under equal biaxial deformation (EB) at temperatures from $80^{\circ} \mathrm{C}$ to $95^{\circ} \mathrm{C}$ is shown in Fig. 2. It can be seen that like other polymeric materials, PLLA material shows viscoelastic behaviour with the stress-strain behaviour changing significantly at various temperature conditions above glass transition. The 
stress can be considered as two parts, the contribution from bond-stretching part due to intermolecular interaction and conformational part by the orientation of molecular chains $[7,8,9]$. At small strains of the deformation process, the bond-stretching stress plays the main role. Because of the small viscosity at these temperature conditions, the initial mechanical response is very smooth and similar at the small strain rates of $1 \mathrm{~s}^{-1}$. This response begins to become obvious between different temperatures at the strain rate of $4 \mathrm{~s}^{-1}$ and $16 \mathrm{~s}^{-1}$. After the nominal strain reaches certain values, enough molecular orientation has reached and there is big strain hardening behaviour at all temperatures. The lower the temperature is, the earlier the onset of strain hardening happens.

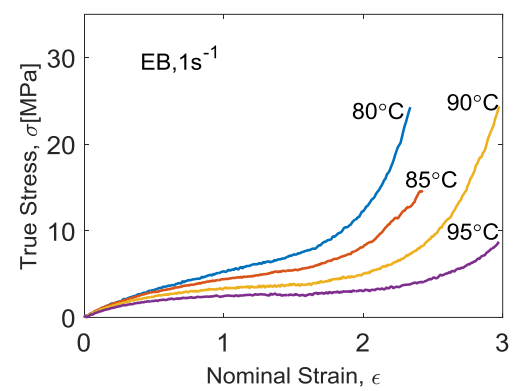

(a)

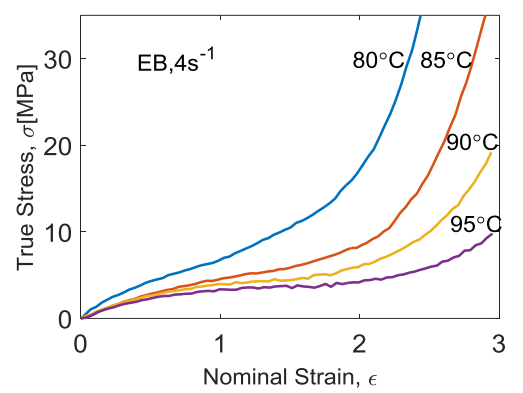

(b)

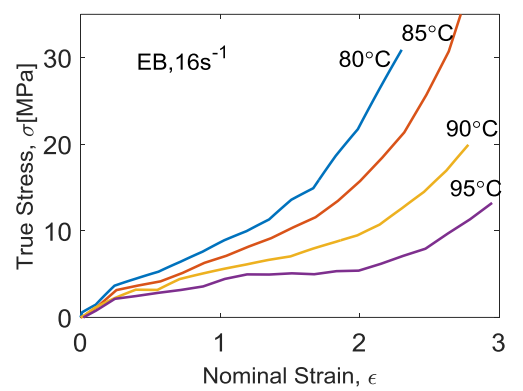

(c)

FIGURE 2. Thermomechanical behavior of PLLA under EB deformation at strain rate of $1 \mathrm{~s}^{-1}(\mathrm{a}), 4 \mathrm{~s}^{-1}(\mathrm{~b})$ and $16 \mathrm{~s}^{-1}(\mathrm{c})$

Under constant-with stretch (CW), the mechanical behaivour of PLLA also shows dependence on temperature, which is shown in Fig. 3. Similar initial stiff response can be also found at CW deformation, which means the stress from bond-stretching part is at the same level with EB deformation. However, at higher strains, the conformational stress in $\mathrm{CW}$ deformation at the same strain is much lower than the corresponding value at EB deformation for the properties of rubbery stretch. At the same time, the strain hardening is also delayed at this deformation mode. In the stretch blow moulding process, the stretch ratio in two directions are always between the EB and CW deformation. As a result, in order to describe this deformation behaviour, the hyper-elastic relations based on strain energy functions have been adopted to get the conformational stress $[7,8,9]$.

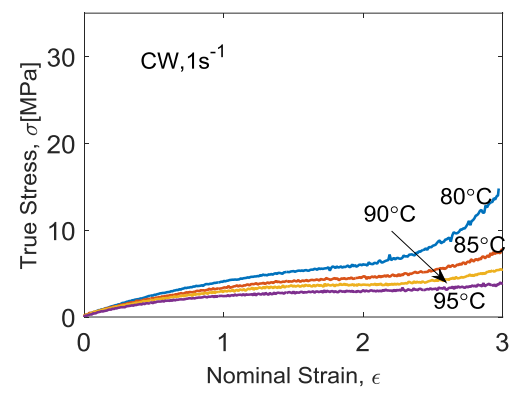

(a)

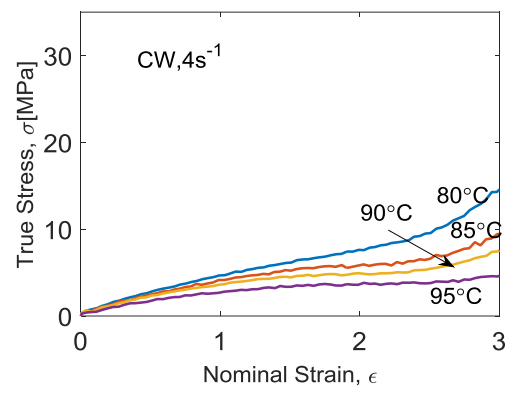

(b)

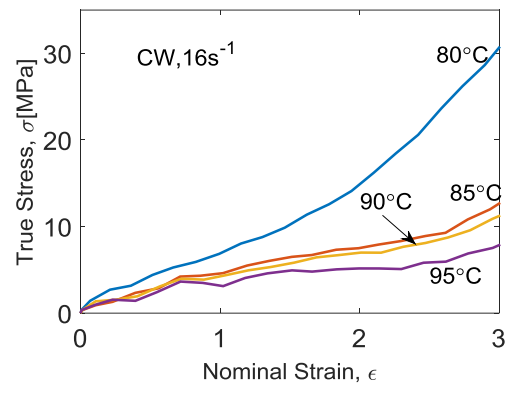

(c)

FIGURE 3. Thermomechanical behavior of PLLA under CW deformation at strain rate of $1 \mathrm{~s}^{-1}(\mathrm{a}), 4 \mathrm{~s}^{-1}$ (b) and $16 \mathrm{~s}^{-1}$ (c)

\section{Thermal Analysis}

The DSC heat flow curves of PLLA materials at temperature ranging from $85^{\circ} \mathrm{C}$ to $95^{\circ} \mathrm{C}$ at the stretch ratio 3.0 and 4.0 after EB deformation are compared with the original curve of PLLA material without stretch, which are shown in Fig. 4 (a). It indicates that the thermal behaviour of PLLA material changed a lot before and after stretch. Three main changes of materials existed in area of the glass transition, cold thermal crystallization and melting. After stretch, the glass transition temperatures become higher because the molecular chains have stronger interaction and need more thermal activation for the transition. It also shows bigger endothermic peak during the transition from glass state to rubbery state in the after-stretch materials. A more obvious cold thermal crystallization just after glass transition 
happens in the after-stretch materials and shows easier crystallization from the contribution of the orientation effect of molecular chains due to biaxial stretch. The final peak during the melting process indicates that there is higher crystallinity from the strain induced crystallization during the stretching process than the materials before stretch.

In order to detect the strain rate effect on the change of microstructure for PLLA materials after stretch, the heat flow curves are obtained for materials after EB deformation at different strain rates with the same stretch ratio at two temperature conditions, which are shown in Fig. 4 (b). The result shows there is no big difference on the crystallinity of the material. The cold thermal crystallization behaviour is also similar to each other. There is a slight difference on the glass transition behaviour and it means the strain hardening effect in the stretching process above glass transition due to strain rates doesn't affect the orientation of molecular chains a lot when a final same stretch ratio can be reached. It can be also concluded that the viscous effect during the stretching process just happens under very local areas among the molecular chains.

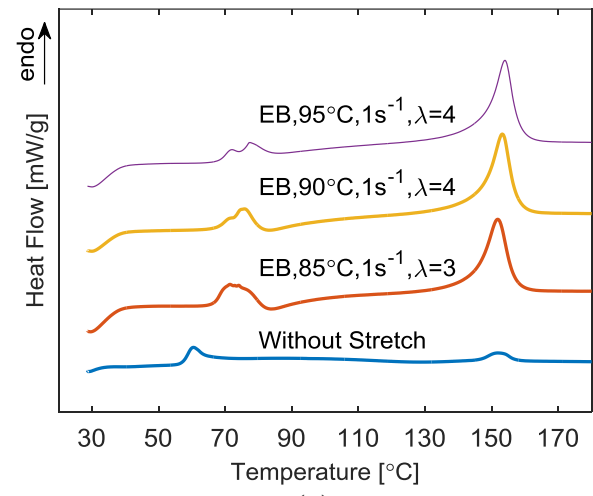

(a)

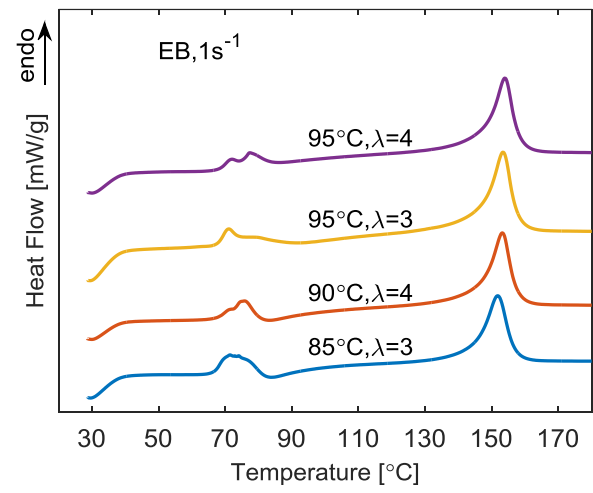

(c)

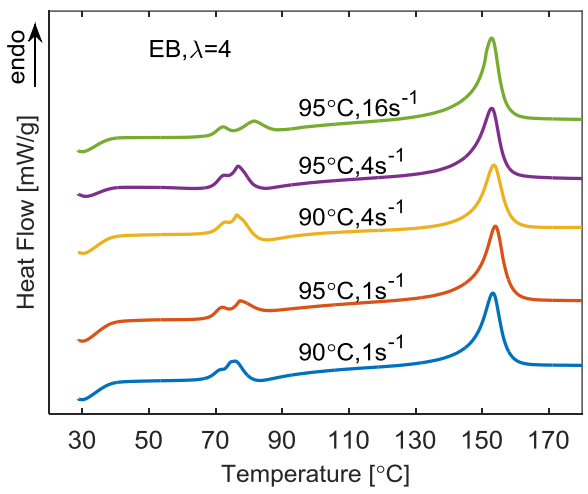

(b)

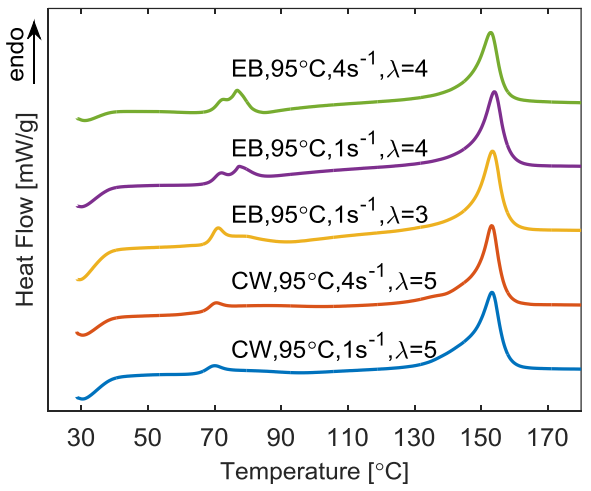

(d)

FIGURE 4. Comparison of DSC curves before and after stretch (a), at different strain rates (b), at different stretch ratio (c) and at different deformation mode (d)

In contrary, by Fig.4 (c), it can be seen that the stretch ratio has a great effect on the microstructure. At bigger stretch ratio, two exothermic peaks exist, which means two kinds of changes in microstructure due to the larger molecular orientation a can be activated by the thermal input during the glass transition. However, at smaller stretch ratio, the less orientation in the molecular chains make a similar kind of change in microstructure. Furthermore, under the same stretch ratio, the orientation effect under lower temperature contributes a more oriented molecular chains, which shows bigger endothermic behaviour.

The deformation mode under biaxial stretch also affect the change of final microstructure. The thermal response of PLLA materials after CW deformation by DSC test is compared with the curves after EB deformation in Fig. 4(d). It shows that at stretch ratio of 5.0, the final crystallinity from $\mathrm{CW}$ deformation is similar to that from $\mathrm{EB}$ deformation. There is no difference between the thermal curves under two strain rates with the same stretch ratio. One small 
exothermic peak happens in the glass transition area, which means that the molecular chains haven't been oriented enough. This is similar to the thermal curve at smaller stretch ratio under EB deformation.

\section{Numerical Modelling}

The model is used to predict the constitutive behaviour at strain rates of $1 \mathrm{~s}^{-1}, 4 \mathrm{~s}^{-1}$ and $16 \mathrm{~s}^{-1}$ under EB deformation, the result of which is shown in Fig.5. It can be seen that temperature dependence of stress-strain behaviour of PLLA has been captured under different strain rates. At strain rate of $1 \mathrm{~s}^{-1}$ and $4 \mathrm{~s}^{-1}$, the simulation results give good agreement at the temperatures ranging from $80^{\circ} \mathrm{C}$ to $95^{\circ} \mathrm{C}$. However, at strain rate of $16 \mathrm{~s}^{-1}$, there is an early onset of strain hardening in the experimental data than the simulation, which means the conformation slippage stopped more early at higher strain rates.

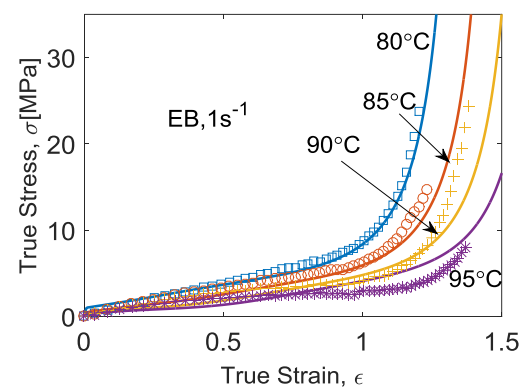

(a)

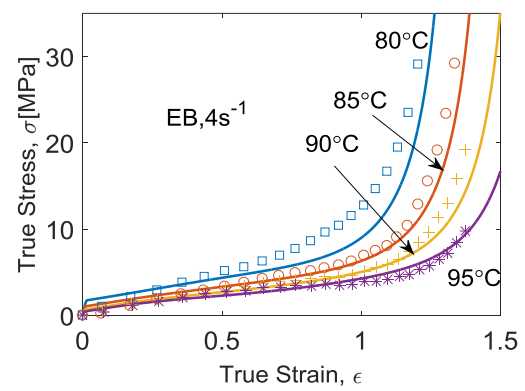

(b)

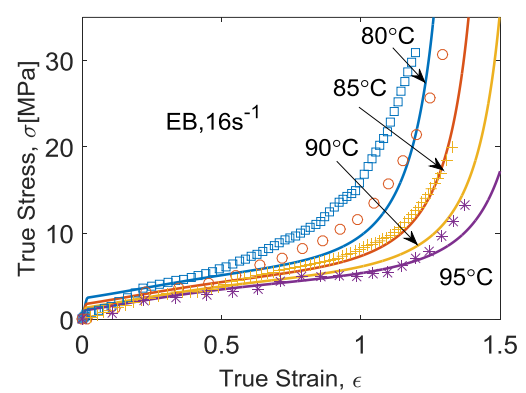

(c)

FIGURE 5. Comparison of results of mechanical behaviour for PLLA from experiment (symbols) and simulation (lines) under EB deformation at strain rate of $1 \mathrm{~s}^{-1}(\mathrm{a}), 4 \mathrm{~s}^{-1}$ (b) and $16 \mathrm{~s}^{-1}$ (c)

\section{CONCLUSIONS}

The thermomechanical properties of PLLA materials at conditions applicable to stretch blow moulding of BVS are investigated by biaxial stretching test and thermal test. The mechanical behaviour of PLLA materials shows strong dependence on temperature and strain rate. The result of mechanical characteristics can help understand the real industrial practice at load-control conditions where different deformation behaviour can happens at forming process. As bigger stretch ratio is required in the circumferential direction than longitudinal direction for manufacturing BVS, the actual deformation shall be between the equal biaxial deformation and constant-width deformation. The mechanical properties of PLLA materials under these two deformation modes can also be obtained by biaxial stretch. The thermal analysis of PLLA materials before and after stretch shows that there is change of microstructure during the deformation process. The effect of strain ratio plays the important role for the thermal response of PLLA materials after-stretch. The presented constitutive model based on GR model can be adopted to simulate the thermomechanical behaviour of PLLA at temperatures above glass transition under biaxial deformation.

\section{REFERENCES}

1. N. Chapleau, and M.A. Huneault, Intern. Polymer Processing 22, 1-8 (2007).

2. T. Glauser and V. Gueriguian, U.S. Patent No. 8,501,079 B2 (6 April 2013)

3. A. Løvdal, and J. W. Andreasen, Polymer International 65, 133-141 (2016).

4. G. H. Menary, and C. G. Armstrong, Plastics, Rubber and Composites 35, 348-354 (2006).

5. G. Stoclet, and R. Seguela, Polymer 53, 519-528 (2012).

6. A. Mahendrasingam, and D. J. Blundell, Polymer 46, 6009-6015 (2005).

7. C. P. Buckley and D. C. Jones, Polymer 36, 3301-3312 (1995).

8. C. P. Buckley and D. C. Jones, Polymer 37, 2403-2414 (1996).

9. A. M. Adams and C. P. Buckley, Polymer 41, 771-786 (2000).

10. H. X. Li and C. P. Buckley, Int. J. Solids and Structures 46, 1607-1623 (2009). 